\title{
Potassium Halide Adducts as Reagent Ions in Infrared Laser Desorption/Ionization Fourier Transform Ion Cyclotron Resonance Mass Spectrometry
}

\author{
Jeremiah D. Hogan and David A. Laude, Jr. \\ Department of Chemistry and Biochemistry, The University of Texas at Austin, Austin, Texas, USA
}

\begin{abstract}
Potassium halide adducts of the form $\mathrm{K}_{2} \mathrm{X}^{+}(\mathrm{X}=\mathrm{F}, \mathrm{Cl}, \mathrm{Br}$, and $\mathrm{I})$ desorbed from neutral salts by high power, pulsed, infrared laser radiation are detected in abundance by Fourier transform-ion cyclotron resonance (FT-ICR) mass spectrometry. FT-ICR detection of the $\mathrm{K}_{2} \mathrm{X}^{+}$adduct is favored at increased laser power densities $\left(>10^{8} \mathrm{~W} / \mathrm{cm}^{2}\right)$ and at trapping potentials below $3 \mathrm{~V}$, independent of $X$. In contrast, detection of $\mathrm{K}^{+}$is promoted at laser power densities below $10^{8} \mathrm{~W} / \mathrm{cm}^{2}$ or at higher trapping potentials, with a threshold for trapping that is strongly dependent on X. When laser desorption/ionization (LDI)/FT-ICR is performed on 1:1 mixtures of $\mathrm{KX}$ and organic molecules, ejection pulses applied continuously at the cyclotron resonance frequency of $\mathrm{K}_{2} \mathrm{X}^{+}$inhibit formation of the cation-attached product, $[\mathrm{M}+\mathrm{K}]^{+}$. Conversely, resonance ejection of $\mathrm{K}^{+}$enhances $[\mathrm{M}+$ $\mathrm{K}^{+}$, apparently by reducing the matrix ion population trapped in the cell. In evaluating higher molecular weight adducts, only $\mathrm{K}_{3} \mathrm{~F}_{2}^{+}$formed in abundance by laser desorption of $\mathrm{KF}$ is found through double resonance experiments to contribute significantly to formation of $[\mathrm{M}+\mathrm{K}]^{+}$. Finally, among the potassium halides, $\mathrm{KI}$ generates the highest ratio of detected $\mathrm{K}_{2} \mathrm{X}^{+}$to $\mathrm{K}^{+}$at low trapping potentials and is therefore best suited for cationtransfer reactions in infrared LDI/FT-ICR experiments performed at power densities in the $10^{8} \mathrm{~W} / \mathrm{cm}^{2}$ range. ( $\mathrm{Am}$ Soc Mass Spectrom 1992, 3, 301-310)
\end{abstract}

$\mathrm{L}$ aser desorption/ionization (LDI) generates analytically useful ions from nonvolatile, large molecular-weight materials that are readily detected by mass spectrometry [1-21]. In these experiments laser wavelength, energy, and power density as well as the composition of the sample matrix are among parameters that define the many distinctly different physical processes that produce such ions. Of specific interest here is the LDI technique in which a short, high energy pulse of infrared radiation from a $\mathrm{CO}_{2}$ or Nd:YAG laser initiates a rapid thermal desorption process. The technique is characterized by formation of abundant $\left[\mathrm{M}+\mathrm{Cl}^{+}\right.$species from the gas-phase attachment of a proton or metal cation, $\mathrm{C}^{+}$, to an intact molecule, $M[5,6]$. Although initially developed for time-of-flight (TOF) mass spectrometry, it is increasingly common to couple infrared LDI with Fourier transform-ion cyclotron resonance (FT-ICR) detection because of superior mass resolution and accuracy in the molecular weight range of interest

Address reprint requests to David A. Laude, Jr., Department of Chemistry and Biochemistry, The University of Texas at Austin, Austin, $1 \times 78712$.
[11-21]. LDI/FT-ICR is commonly performed at power densities in the $10^{8} \mathrm{~W} / \mathrm{cm}^{2}$ range on samples consisting of the analyte molecule and an alkali metal halide deposited on a stainless steel surface [11]. Under these conditions abundant $\left[\mathrm{M}+\mathrm{Cl}^{+}\right.$is observed in a spectrum often devoid of fragment or matrix ions. The range of important chemical and biological classes of compounds that are amenable to this type of ionization is large, encompassing most polar molecules in the molecular weight range to several thousand units.

Much is now known from TOF studies about the mechanism for formation of the cation-attached product. The desorption event must initiate rapid thermal heating of the sample and substrate on the $10^{-7}$ to $10^{-9} \mathrm{~s}$ time scale at power densities exceeding $10^{6}$ $\mathrm{W} / \mathrm{cm}^{2}$ to generate high surface temperatures that vaporize and ionize the salt $[7,8]$. Coincidentally, a substantial fraction of sample molecules will exit the surface intact because insufficient time is available for bond rupture associated with internalization of laser energy. Within the complex ensemble of charged and neutral particles that evolve from the desorption site are sizable populations of the precursor cations and sample molecules that subsequently undergo reactive 
gas-phase collisions to form $\left[\mathrm{M}+\mathrm{C}^{+}\right.$products with average kinetic energies of less than $1 \mathrm{eV}$ [10]. The extent to which these reactions occur is evidently dependent upon a gas-phase spatial and temporal overlap of the reactive species in the evolving plasma and thus is a complicated function of ion and neutral velocities, trajectories, and desorption times.

It is uncertain whether the mechanism for generating the cation-attachment product detected by TOF can be extended to LDI/FT-ICR. This is because even under identical sample preparation and laser desorption conditions, many differences exist between the two mass analyzers that potentially discriminate in both formation and detection of the ions. Differences include the orientation and distance between the desorption site and entrance to the mass analyzer, the time lag between desorption and detection events, the strong confining and directional influences of the FTICR magnetic field on the desorbed plasma, and the discrimination against high energy ions imposed by the modest trapping felds in the FT-ICR. Until recently FT-ICR experiments had not been performed specifically to evaluate the mechanisms for ion formation and trapping in the infrared laser desorption experiment. However, in a series of split probe experiments, Chiarelli and Gross [20, 21] verified that cation-attached products detected by FT-ICR were formed in the gas phase. This work did not, however, address the question of how these ions were trapped in the cell for detection. Moreover, these studies were performed at two power densities, $10^{6} \mathrm{~W} / \mathrm{cm}^{2}$ and $10^{10} \mathrm{~W} / \mathrm{cm}^{2}$, but did not include the region around $10^{8} \mathrm{~W} / \mathrm{cm}^{2}$ that is often employed for LDI/FT-ICR work. As will be demonstrated, the selection of laser power density for the experiment strongly influences the composition and kinetic energy distribution of reactants in the desorbed plasma and consequently alters the size and composition of the product ions that are detected by FT-ICR.

Recently we designed a probe-mounted fiber-optic assembly with which to better evaluate the LDI/FTICR experiment [22]. Initial probe displacement experiments were performed to distinguish the manner in which various desorbed ions were trapped for detection. For example, metal ions desorbed under plasma ignition conditions generated FT-ICR signal intensities that were invariant to probe displacement. This contrasted with the application of infrared LDI to organic molecules to be discussed here in that signal intensities for cation-attached species exhibited a strong dependence on proximity of the desorption site to the trapped ion cell. This variation in signal intensity is consistent with a gas-phase transfer process because it can be explained by differences in velocity profiles for the ion and neutral reactants. In a later study variable trapping potential and double resonance experiments confirmed that formation of the cation-attached species is a gas-phase phenomenon that actually occurs in the trapped ion cell [23]. Those double resonance experi- ments also indicated that the precursor ion for the reaction was not the bare cation but rather an adduct of the salt. Specifically, when $\mathrm{KBr}$ was mixed with the organic samples, $\mathrm{K}_{2} \mathrm{Br}^{+}$rather than $\mathrm{K}^{+}$was found to react with $M$ to produce $[M+K]^{+}$. This work has in common with other LDI [24] and high energy particle experiments [25-27] the observation of salt adducts of the form $\left[\mathrm{C}_{x} \mathrm{X}_{\mathrm{x}-1}\right]^{+}$. In particular, Russell and coworkers [25] proposed that these salt adducts could serve as precursors for cation-attached species of the form $[\mathrm{M}+\mathrm{C}]^{+}$and $\left[\mathrm{M}+\mathrm{C}_{\mathrm{x}}+\mathrm{H}_{\mathrm{x}-1}\right]^{+}$detected by secondary ion mass spectrometry (SIMS) [25].

In work to be presented, a more thorough investigation is conducted into the desorption and trapping mechanisms associated with infrared LDI/FT-ICR. Of specific interest is the use of FT-ICR to evaluate the origin, properties, and reactivities of potassium halide adducts in comparison with $\mathrm{K}^{+}$at power densities of $10^{8} \mathrm{~W} / \mathrm{cm}^{2}$. Assuming that at these power densities adduct formation is a prerequisite for production of abundant $[\mathbf{M}+\mathbf{K}]^{+}$, LDI and FT-ICR conditions that maximize formation and trapping of these adducts from the pure salt will be sought. This knowledge is then applied in FT-ICR double resonance and variable trap potential studies to determine conditions under which $[\mathrm{M}+\mathrm{K}]^{+}$formed from mixtures of potassium salt and organic molecules is trapped and detected in highest yield.

\section{Experimental}

Instrumentation. All experiments were performed with a Fourier transform mass spectrometer assembled with components that constitute much of the FT-ICR-2000 Fourier transform mass spectrometer originally marketed by Nicolet Analytical Instruments (Madison, WI). These include a 3.0 T superconducting magnet, differentially diffusion-pumped ultrahigh vacuum chamber operating at base pressures in the mid- $10^{-9}$ torr range, adjacent $4.76 \mathrm{~cm}$ cubic stainless steel dual trapped ion cells, and standard cell controller, high power excitation amplifier, preamplifier, and Nicolet 1280 data station. A Spectra Physics (Mounlain View, CA) DCR-11 Nd: YAG laser capable of $275 \mathrm{~mJ}$ pulses at $1064 \mathrm{~nm}$ was interfaced through a probe-mounted fiber-optic interface to the FT-ICR [22]. In the single-shot mode used for all experiments fluctuations in laser energy from shot to shot were less than $10 \%$.

Sample preparation. A demountable stainless steel probe tip with cylindrical geometry $(20 \mathrm{~mm}$ length $\times 5$ min diameter) was used for all experiments. Samples were dissolved in a suitable solvent and aerosoldeposited onto a spinning tip to provide uniform coverage and remove excess solvent. After drying in a vacuum oven the probe tip was appended to a $1 / 4^{\prime \prime}$ diameter sample probe that was mounted inside the larger fiber-optic probe assembly. The fiber optic was 
positioned about $1 \mathrm{~mm}$ from the sample tip at a $30^{\circ}$ angle to the surface, which produced a $0.9 \mathrm{~mm}^{2}$ spot size for unfocused exiting laser light. Rotation and translation of the sample probe permitted several hundred laser firings on fresh sample without disturbing the orientation of the desorption site with respect to the trapped ion cell.

Two types of samples were prepared. In initial studies with the pure salt, analytical grade $\mathrm{KF}, \mathrm{KCl}$, $\mathrm{KBr}$, and $\mathrm{KI}$ salts were dissolved in a water/acetone solution and sprayed onto the probe tip. In later experiments the organic material used to evaluate the cation-transfer process was dilaurylthiodiproprionate (DLTDP). In this case the sample tip was prepared by furst depositing the potassium salt onto the tip as described above, followed by deposition of a DLTDP/methylene chloride solution on top of the salt layer. DLTDP was chosen because it deposits uniformly and generates reproducible spectra with abundant $[\mathrm{M}+\mathrm{K}]^{+}$signal intensities. Another advantage of DLTDP is a low room temperature vapor pressure that minimizes interfering gas-phase reactions with background neutrals. At temperatures above $170{ }^{\circ} \mathrm{C}$, however, DLTDP vapor pressure is in the mid $10^{-8}$ torr range and reactions with gas-phase species do accur.

Laser desorption conditions. Spectra were acquired from a single laser fring of the isolated 1064-nm wavelength at a fresh sample surface. Unless otherwise noted, a power density of $3 \times 10^{8} \mathrm{~W} / \mathrm{cm}^{2}$, based on $22 \mathrm{~mJ}$ of energy fucused through the fiber in a 8-ns laser pulse, was deposited at the sample. For most experiments the fiber-optic assembly was positioned 8 $\mathrm{cm}$ from the front trap plate with the desorbed ion cloud formed along the z-axis center line of the cell. In this position reproducibility was improved because space charge effects were less severe than when the probe was positioned close to the cell. This position also favored trapping of salt adduct ions over $\mathrm{K}^{+}$.

Data acquisition parameters. The LDI/FT-ICR experiment pulse sequence commenced with a quench delay to remove ions from the cell after which trap potentials were set to $2.0 \mathrm{~V}$ for the duration of the sequence. A trigger pulse from the data station then initiated a single firing of the laser. For much of the work a delay of $150 \mathrm{~ms}$ followed to allow for a return to system base pressures. Shorter delay times yielded less consistent signal intensities but ion-molecule reactions occurred at longer delays. Consecutive single radiofrequency pulses were used as needed for selective ejection during the delay period. The first ejection event, applied concurrently with triggering of the laser, was used to verify ions suspected as precursors in ion-molecule reactions associated with laser desorption. Subsequent ejection pulses were used to remove undesirable ions that would contribute to space charge in the cell. Broadband excitation preceding the detection event was usually accomplished with a radiofrequency sweep over a $2.66 \mathrm{MHz}$ bandwidth at a sweep rate of $1000 \mathrm{~Hz} / \mu \mathrm{s}$. Broadband detection was then performed with $32 \mathrm{~K}$ data points acquired over a $1.33 \mathrm{MHz}$ bandwidth during a $833-\mu$ s detection period. These parameters were adequate to provide nominal mass resolution for all ions of interest.

For several experiments it was necessary to supplement the standard FT-ICR-2000 hardware. A systemimposed trap potential maximum of $10 \mathrm{~V}$ was extended to $200 \mathrm{~V}$ in variable potential studies by adding an external power supply. Also, as an alternative to swept or single frequency excitation, a synthesized excitation waveform consisting of the superimposed sinewaves corresponding to the cyclotron frequency of ions of interest was sometimes used. This multiple frequency excitation waveform was created with a LeCroy (Chestnut Ridge, NY) Model 9100 arbitrary function generator that was substituted for the Extrel synthesizer. This type of waveform was particularly useful when simultaneous ejection of several types of ions was required. For example, it was used here to eject various combinations of $\mathrm{K}^{+}, \mathrm{K}_{2} \mathrm{~F}^{+}$, and $\mathrm{K}_{3} \mathrm{~F}_{2}^{+}$ during experiments to determine $\mathrm{KF}$ reaction precursors.

FT-ICR spectral data processing of the transient included zero-filling, sine-bell apodization, and Fourier transformation. Relative peak magnitudes and mass resolution values were obtained from standard software routines. System calibration was simplified by using the $\mathrm{KX}$ adducts present in each spectrum as calibrant ions.

\section{Results and Discussion}

Infrared LDI of potassium halides. As a prelude to studies on adduct reactivity with organic molecules in the LDI/FT-ICR experiment, LDI was performed on the pure potassium halide salts. One immediate observation from this work was that laser and mass spectrometer parameters could be selected to preferentially trap and detect either $\mathrm{K}^{+}$or $\mathrm{K}_{2} \mathrm{X}^{+}$. These parameters include trapping potential, laser power density, probe displacement, and sample preparation. Each is discussed below.

Variable trapping potential studies were performed in which $\mathrm{K}^{+}$and $\mathrm{K}_{2} \mathrm{X}^{+}$abundances were measured. Presented first in Figure 1 are the trapping patential profiles for $\mathrm{K}^{+}$formed by LDI at $3 \times 10^{8} \mathrm{~W} / \mathrm{cm}^{2}$ on pure $\mathrm{KF}, \mathrm{KCl}, \mathrm{KBr}$, or $\mathrm{KI}$. In each case, beyond a threshold that differed with $X, K^{+}$was observed in increasing amounts as trap potential increased. A correlation between decreasing lattice energy of the salt and increasing detection threshold of $\mathrm{K}^{+}$is observed. All profiles terminate at a trapping potential beyond which a leveling of signal intensity indicates the trapped ion cell capacity for linear response in FT-ICR detection has been reached. Because the trap- 


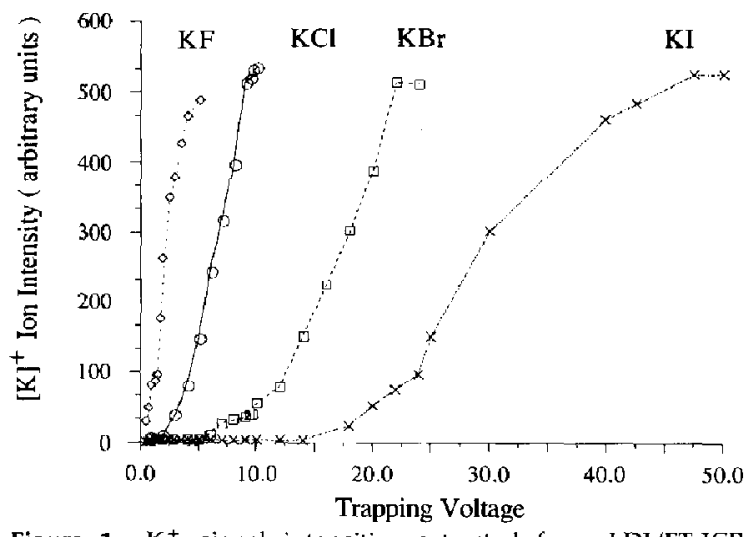

Figure 1. $\mathrm{K}^{+}$signal intensities extracted from LDI/FT-ICR spectra of pure $\mathrm{KF}, \mathrm{KCl}, \mathrm{KBr}$, and $\mathrm{KI}$ at increasing trap potentials. Termination of each profile occurs at the onset of space charge.

ping mechanism is unclear, we cannot distinguish whether the differences in Figure 1 can be attributed to differences in kinetic energy or to electric field effects at the cell. However, these differences in $\mathrm{K}^{+}$ behavior suggest that the choice of salt may be critical to infrared LDI/FT-ICR detection of organic molecules.

Turning to an examination of the $\mathrm{K}_{2} \mathrm{X}^{+}$adduct, Figure 2 presents variable trapping profiles for $\mathrm{KF}$ and KI salts acquired at laser power densities of $3 \times 10^{8}$ $\mathrm{W} / \mathrm{cm}^{2}$ and $7 \times 10^{7} \mathrm{~W} / \mathrm{cm}^{2}$. Seen in these data are features common to $\mathrm{K}^{+}$and $\mathrm{K}_{2} \mathrm{X}^{+}$profiles for each salt that are of consequence to the formation and detection of $[\mathrm{M}+\mathrm{K}]^{+}$. At power densities of $3 \times 10^{8}$ $W / \mathrm{cm}^{2}$, efficient trapping of $K_{2} X^{+}$adducts occurs at much lower potentials than for the bare cation; there is also less dependence on $X$. It has been shown that $[\mathrm{M}+\mathrm{K}]^{+}$intensity is strongly dependent upon laser power density in the infrared LDI/FT-ICR experiment $[22,29,30]$ and in general increases with increasing laser power in the range around $10^{8} \mathrm{~W} / \mathrm{cm}^{2}$. Although this observation might be attributed to variations in the desorption of intact $M$, the profiles in Figure 2 acquired at power densities of $7 \times 10^{7} \mathrm{~W} / \mathrm{cm}^{2}$ and $3 \times 10^{8} \mathrm{~W} / \mathrm{cm}^{2}$ suggest an additional explanation. For both $\mathrm{KF}$ and $\mathrm{KI}$, the ratio of adduct to $\mathrm{K}^{+}$ decreases with decreasing power densities, and below $10^{7} \mathrm{~W} / \mathrm{cm}^{2}$ only $\mathrm{K}^{+}$is observed. If $[\mathrm{M}+\mathrm{K}]^{+}$formation depends upon $\mathrm{K}_{2} \mathrm{X}^{+}$formation, as the FT-ICR double resonance experiments will show, then higher laser power densities are desirable. From a practical perspective, a distinction between the individual salts can also be made based upon the extent to which overlap of $\mathrm{K}_{2} \mathrm{X}^{+}$and $\mathrm{K}^{+}$distributions occurs at different trapping potentials. For example, in the higher laser power density examples in Figure $2, \mathrm{~K}^{+}$and $\mathrm{K}_{2} \mathrm{I}^{+}$profiles are almost completely resolved while $\mathrm{K}^{+}$and $\mathrm{K}_{2} \mathrm{~F}^{+}$exhibit considerable overlap. Assuming that only adduct ions are involved in $[M+K]^{+}$for- mation and that $\mathrm{K}^{+}$only hinders detection by reducing trapped ion cell capacity for the reactive species, then KI should be a superior salt to KF at the lower trapping potentials used for detection of $[\mathbf{M}+\mathbf{K}]^{+}$.

In comparing the four potassium halides it was desirable to determine which would generate $\mathrm{K}_{2} \mathrm{X}^{+}$ in highest yield. Comparisons from sample to sample are difficult because of irreproducibility in sample preparation and experiment execution. To obtain a more direct comparison equal quantities of each salt were blended into a mixture and deposited on the probe. The spectrum in Figure 3, obtained with $\mathrm{K}^{+}$ continuously ejected, is representative of those obtained for the mixture at high laser power and a $2.0 \mathrm{~V}$ trapping potential. The relative ranking in terms of peak areas for combined isotopes of each adduct is $\mathrm{K}_{2} \mathrm{I}^{+}>\mathrm{K}_{2} \mathrm{Br}^{+}>\mathrm{K}_{2} \mathrm{Cl}^{+} \approx \mathrm{K}_{2} \mathrm{~F}^{+}$.

In considering the origin of the adduct, it is possible that intact $\mathrm{K}_{2} \mathrm{X}^{+}$exits the desorption site and then penetrates the trapping fields and is retained for detection; alternatively, the adduct could be generated in the cell by gas-phase attachment of $K^{+}$to the neutral salt or by decomposition from larger adducts. To investigate possible precursors to the $\mathrm{K}_{2} \mathrm{X}^{+}$adduct, several double resonance experiments were performed. One example, shown in Figure 4, presents profiles of the time delay between the desorption event and detection, during which $\mathrm{K}^{+}$is either continuously ejected or allowed to accumulate with $\mathrm{K}_{2} \mathrm{Br}^{+}$ in the cell. The control in Figure $4 \mathrm{a}$ indicates that in the absence of an ejection event, both $\mathrm{K}^{+}$and $\mathrm{K}_{2} \mathrm{Br}^{+}$ are immediately detected and at longer delays remain in a fixed proportion. In Figure $4 \mathrm{~b}$ the $\mathrm{K}^{+}$is ejected continuously between desorption and detection and the $\mathrm{K}_{2} \mathrm{Br}^{+}$is observed in higher abundance. This indicates that not only is $\mathrm{K}^{+}$not the precursor to $\mathrm{K}_{2} \mathrm{Br}^{+}$detected by FTICR, but its ejection actually enhances $\mathrm{K}_{2} \mathrm{Br}^{+}$intensity because of the increase in trapped ion cell capacity. Double resonance experiments to determine whether $\mathrm{K}_{3} \mathrm{Br}_{2}^{+}$and $\mathrm{K}_{4} \mathrm{Br}_{3}^{+}$decompose to form $\mathrm{K}_{2} \mathrm{Br}^{+}$also yielded negative results.

The ejection experiments argue against $K_{2} X^{+}$formation in the cell although decomposition of neutral adducts is not ruled out. More plausible, however, is the generation of $\mathrm{K}_{2} \mathrm{X}^{+}$at or near the desorption site. This would require a mechanism to promote the injection and retention of these externally generated ions in trapping fields maintained at constant potentials [31-34]. The ability to trap $\mathrm{K}^{+}$for detection also requires such a mechanism. An explanation we have investigated that is most consistent with LDI invokes Debye shielding of low energy ions in quasi-neutral plasmas as a means for low energy ions to penetrate the trapping fields [35]. Although we demonstrate the effect for metal targets that generate a dense, high energy plasma by laser plasma ignition [36-38], it may also apply to laser desorption of salts.

Brief mention is now made of two other factors that influence FT-ICR detection of $\mathrm{K}^{+}$or $\mathrm{K}_{2} \mathrm{X}^{+}$. In 

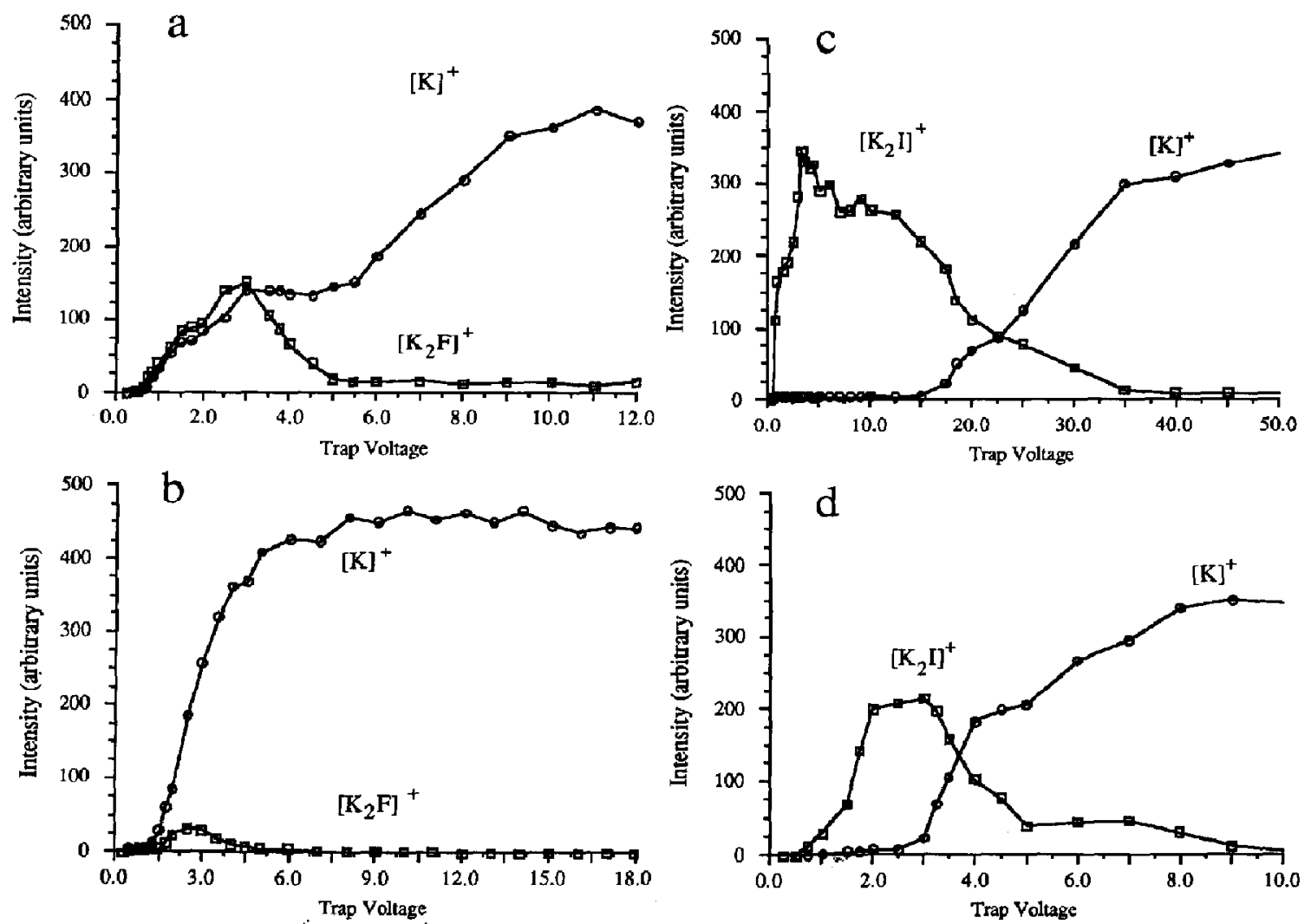

Figure 2. $\mathrm{K}^{+}$and $\mathrm{K}_{2} x^{+}$signal magnitudes from LDI/FT-ICR spectra of $\mathrm{KF}$ and $\mathrm{KI}$ salts at increasing trap potentials: (a) KF sample at laser power density of $3 \times 10^{8} \mathrm{~W} / \mathrm{cm}^{2}$; (b) KF sample at laser power density of $7 \times 10^{7} \mathrm{~W} / \mathrm{cm}^{2}$; (c) KI sample at laser power density of $3 \times 10^{8} \mathrm{~W} / \mathrm{cm}^{2}$;

(d) KI sample at laser power density of $7 \times 10^{7} \mathrm{~W} / \mathrm{cm}^{2}$.

general, as probe displacement from the trapped ion cell increases, the trapping of $\mathrm{K}^{+}$is favored [22]. One explanation is that the higher energy $\mathrm{K}^{+}$is less likely than $\mathrm{K}_{2} \mathrm{X}^{+}$to be reflected in magnetic fields that decrease in magnitude and homogeneity. Typically, we position the probe within $8 \mathrm{~cm}$ of the trapped ion cell to select for $\mathrm{K}_{2} \mathrm{X}^{+}$and beyond $15 \mathrm{~cm}$ to select for $\mathrm{K}^{+}$. Another factor that strongly influences adduct formation is sample preparation. Although controlled studies were not performed, we have found qualitatively that increased hydration of the sample favors adduct formation. With respect to $[\mathrm{M}+\mathrm{K}]^{+}$formation, this suggests that scrupulous drying of the samples is counterproductive.

Before turning to a discussion of cation-transfer reactions with laser desorbed organic molecules, it should be stressed that an understanding of this gasphase chemistry requires not only characterization of the ion, which was the focus of the work presented, but also the behavior of the desorbed molecule, which has not been discussed. Unfortunately, in our instrument it is not possible to evaluate these neutrals by mass spectrometry without a secondary ion source.
As a result, laser power density and matrix effects on the spatial and temporal evolution of the neutral can only be indirectly inferred from the cation-transfer reaction itself. Interpretation of the data to be presented in the next section is thus made more speculative than would be desired.

Adduct reactions with $M$. We recently demonstrated through FT-ICR double resonance experiments that laser desorbed $\mathrm{K}_{2} \mathrm{Br}^{+}$can serve as a precursor ion in reaction with DLTDP to form a cation-transfer product [23]. Presented in Figure 5 are double resonance and control profiles performed to uncover the dynamics of this reaction in the trapped ion cell. For each profile the relative abundance of the $[\mathrm{M}+\mathrm{K}]^{+}$species formed by $\mathrm{LDI}$ of $\mathrm{KBr}$ and DLTDP was monitored by FT-ICR. The probe was positioned $15 \mathrm{~cm}$ from the cell to allow a significant time lag between the desorption event and arrival of the plasma at the trapped ion cell. A variable offset delay, the independent variable in Figure 5, was inserted into the FT-ICR pulse sequence preceding a 2-s ejection pulse applied to $\mathrm{K}^{+}$or $\mathrm{K}_{2} \mathrm{Br}^{+}$. In the control experiment no ejection pulse was used 


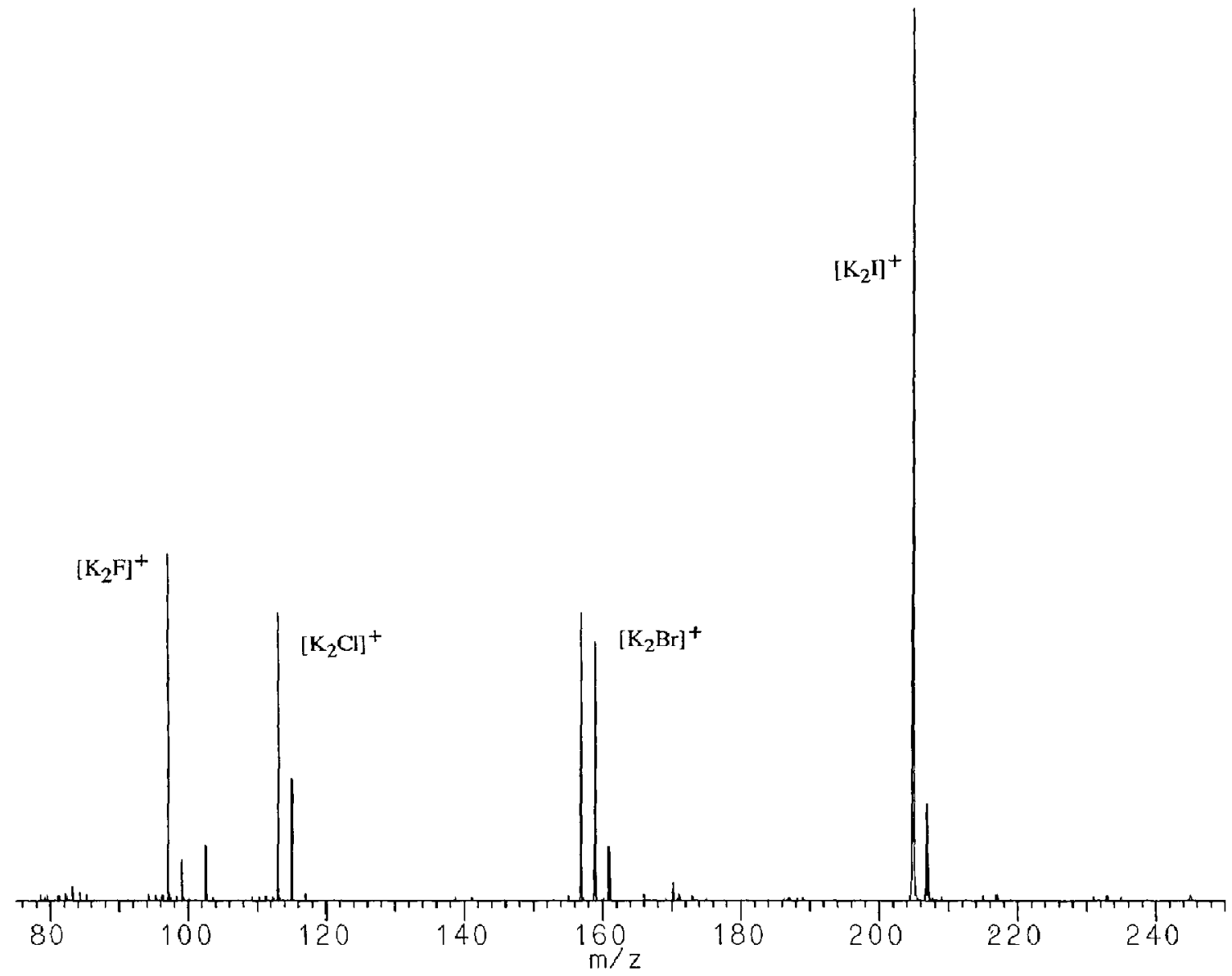

Figure 3. FT-ICR spectrum of an equimolar mixture of $\mathrm{KF}, \mathrm{KCl}, \mathrm{KBr}$, and $\mathrm{KI}$ salts acquired at 2.0 $\mathrm{V}$ trap potentials with $\mathrm{K}^{+}$ejection following LDI at $3 \times 10^{8} \mathrm{~W} / \mathrm{cm}^{2}$.

and, as would be expected, the $[\mathrm{M}+\mathrm{K}]^{+}$signal intensity remained constant over a combined delay periad consisting of the variable delay and the 2-s ejection pulse. The presence of interfering $\mathrm{K}^{+}$ions in the limited cell volume reduced the relative abundance of $[\mathrm{M}+\mathrm{K}]^{+}$.

The profile presented in Figure 5 for $\mathrm{K}^{+}$ejection at increasing offset times generates $[\mathrm{M}+\mathrm{K}]^{+}$at all times in higher yield than the control experiment, which suggests that $\mathrm{K}^{+}$is not the precursor ion. The profile also indicates that $\mathrm{K}^{+}$arrival at the cell precedes $[\mathrm{M}+\mathrm{K}]^{+}$formation. The large increase in $[\mathrm{M}+\mathrm{K}]^{+}$ abundance between 1 and $2 \mathrm{~ms}$ corresponds to ejection of arriving $\mathrm{K}^{+}$at a time when it might have occupied the cell prior to arrival of the neutral organic molecule. Ejection of $\mathrm{K}^{+}$at longer offset delays is of decreasing benefit because the transient neutral organic population is no longer present in the cell to form $[\mathbf{M}+\mathbf{K}]^{+}$.

The Figure 5 ejection profile for $\mathrm{K}_{2} \mathrm{Br}^{+}$suggests a very different role for the adduct in formation of
$[\mathrm{M}+\mathrm{K}]^{+}$detected by FT-ICR. The most striking difference is that if the ejection event is applied during the first $2 \mathrm{~ms}$ after desorption, no $[\mathrm{M}+\mathrm{K}]^{+}$is formed. This can be explained if $\mathrm{K}_{2} \mathrm{Br}^{+}$is the precursor ion in the cation-transfer reaction and the delay corresponds to a time pcriod during which the resonance ejection commences prior to arrival of the $\mathrm{K}_{2} \mathrm{Br}^{+}$or $\mathrm{M}$ at the trapped ion cell. Consistent with this argument is the growth of $[\mathrm{M}+\mathrm{K}]^{+}$at longer delays prior to ejection during which both reactants have time to reach the cell, react, and accumulate $[\mathrm{M}+\mathrm{K}]^{+}$. Again, because $\mathrm{K}^{+}$was present in the cell during these experiments, $[\mathrm{M}+\mathrm{K}]^{+}$abundances were depressed.

Reactions of larger adducts. It was of interest to determine to what extent larger salt adducts of the form $\left[K_{x} X_{x-1}\right]^{+}$reacted with $M$. Our experience with LDI of the pure salts is that at power densities around $10^{8}$ $\mathrm{W} / \mathrm{cm}^{2}, \mathrm{~K}_{2} \mathrm{X}^{+}$formation predominates with only small amounts of $\mathrm{K}_{3} \mathrm{X}_{2}^{+}$and $\mathrm{K}_{4} \mathrm{X}_{3}^{+}$detected by FTICR. KF is the salt that most readily forms the larger 

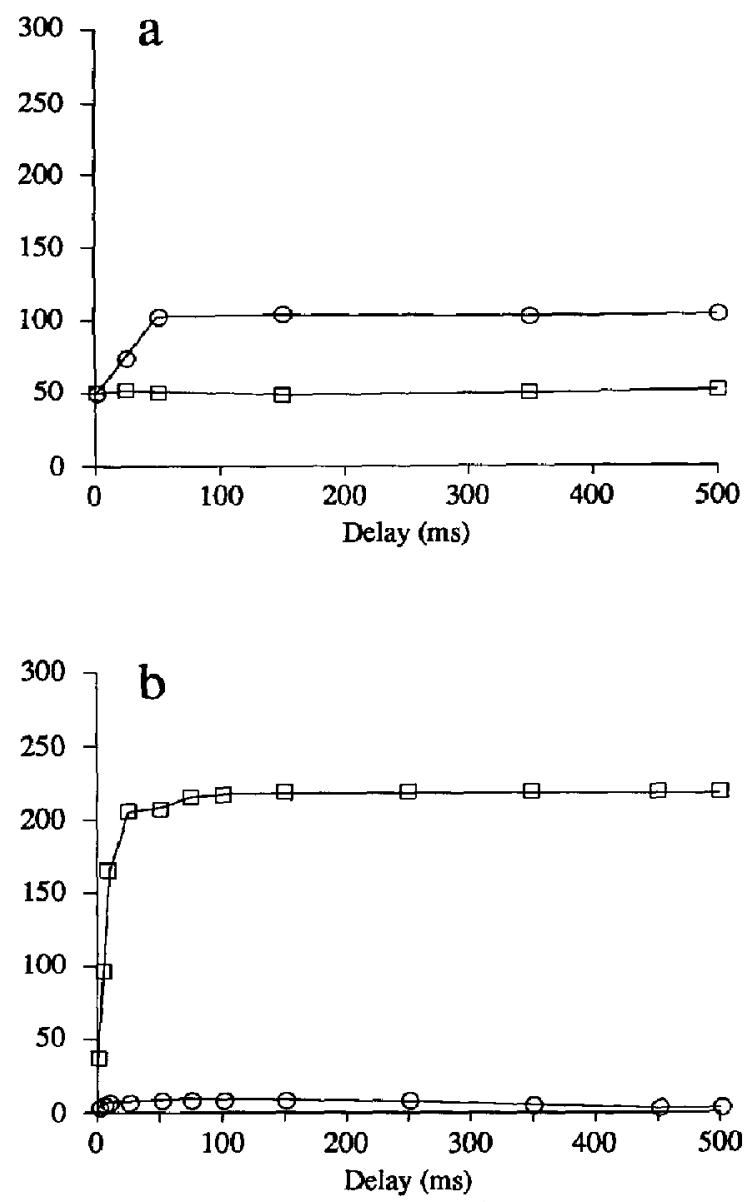

Figure 4. FT-ICR profiles of $\mathrm{K}^{+}(\mathrm{O})$ and $\mathrm{K}_{2} \mathrm{Br}^{+}(\square)$ signal magnitude at increasing delays after LDI at $3 \times 10^{8} \mathrm{~W} / \mathrm{cm}^{2}$ on a $\mathrm{KBr}$ sample. (a) Standard LDI/FT-ICR pulse sequence with no ejection events and (b) LDI/FT-ICR pulse sequence with continuous ejection of $\mathrm{K}^{+}$prior to detection.

adducts so a series of double and triple resonance experiments involving $\mathrm{K}^{+}, \mathrm{K}_{2} \mathrm{~F}^{+}$, and $\mathrm{K}_{3} \mathrm{~F}_{2}^{+}$reactions with DLTDP were conducted. All eight combinations of ejection and control experiments were performed, and LDI/FT-ICR spectra for four of these are shown in Figure 6. The relative abundance of $\left[\mathrm{M}+\mathrm{K}^{+}\right.$in these spectra can be explained by recognizing that ejection pulses influence the $[\mathrm{M}+\mathrm{K}]^{+}$in the two ways discussed for Figure 5. On the one hand, ejection can enhance the signal by reducing the concentration of matrix ions present in the cell at the time of ion formation and later detection. Conversely, ejection events that remove precursor ions will attenuate the $[\mathrm{M}+\mathrm{K}]^{+}$signal. Consistency in explaining $[\mathrm{M}+$ $\mathrm{Kl}^{+}$abundances in Figure 6 is obtained if the following assumptions are made: $\mathrm{K}^{+}$contributes little to $[M+K]^{+}$formation but is a strong matrix interfer-

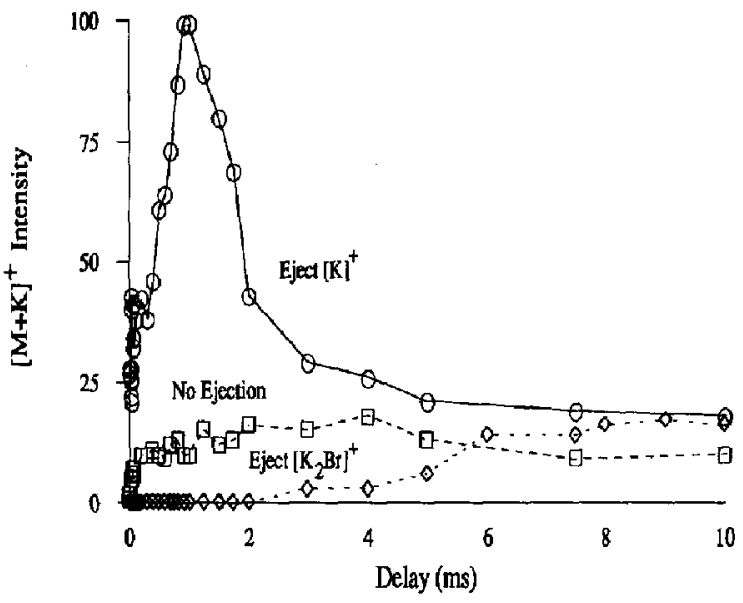

Figure 5. LDI/FT-ICR profiles of $[\mathrm{M}+\mathrm{K}]^{+}$relative abundance as time between laser firing and application of a $2 \mathrm{~s}$ ejection pulse is increased. Profiles are presented for a control experiment in which resonance ejection is not used $(\square)$ and double resonance experiments in which $K^{+}(O)$ and $K_{2} B r^{+}(\theta)$ are ejected. The sample is a mixture of $\mathrm{KBr}$ and DLTDP.
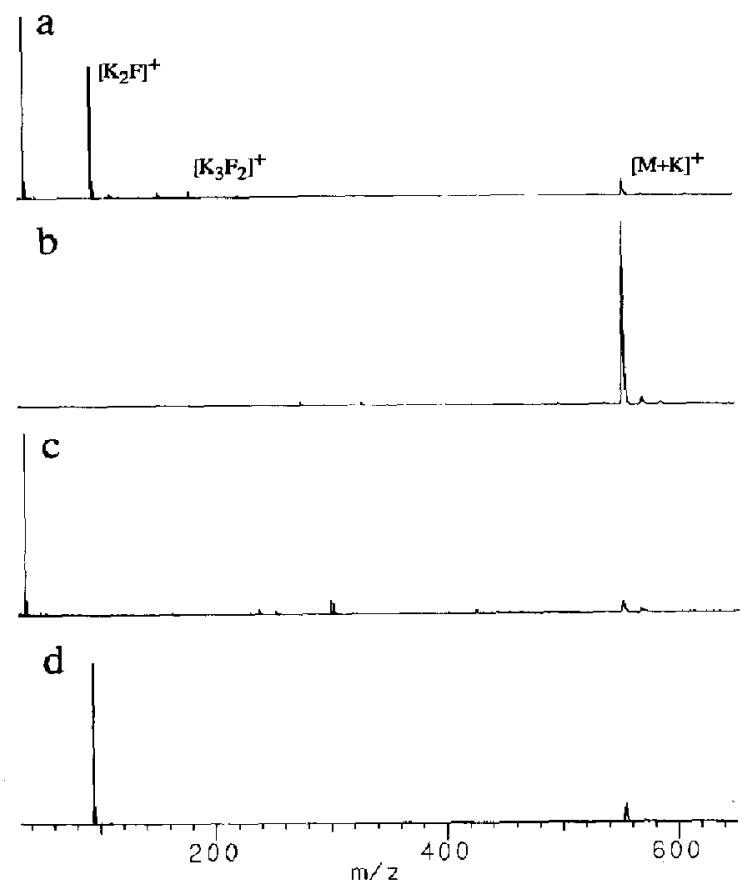

Figure 6. FT-ICR spectra of a DLTDP and KF mixture following $\mathrm{LDI}$ at $3 \times 10^{8} \mathrm{~W} / \mathrm{cm}^{2}$. Suspected precursor ions were removed from the trapped ion cell by applying radiofrequency excitation at the cyclotron frequencies of the following ions: (a) no ejection; (b) ejection of $\mathrm{K}^{+}$and $\mathrm{K}_{2} \mathrm{~F}^{+}$; (c) ejection of $\mathrm{K}_{2} \mathrm{~F}^{+}$ and $\mathrm{K}_{3} \mathrm{~F}_{2}^{+}$; (d) ejection of $\mathrm{K}^{+}$and $\mathrm{K}_{3} \mathrm{~F}_{2}^{+}$. 
ence ion; $\mathrm{K}_{3} \mathrm{~F}_{2}^{+}$is a precursor ion for $[\mathrm{M}+\mathrm{K}]^{+}$, but is sufficiently reactive or unstable that it is not detected in high quantities as a matrix ion; $\mathrm{K}_{2} \mathrm{~F}^{\mathrm{t}}$ is a precursor for $[\mathrm{M}+\mathrm{K}]^{+}$but is also present in sufficient yield at detection that it suppresses the $[\mathrm{M}+\mathrm{K}]^{+}$signal.

In support of these assumptions, the spectrum in Figure 6a acquired as a control without ejection events allows $\mathrm{K}^{+}$and $\mathrm{K}_{2} \mathrm{~F}^{+}$to fill the cell and suppress the $[\mathrm{M}+\mathrm{K}]^{+}$. In Figure $6 \mathrm{~b}$, when both $\mathrm{K}^{+}$and $\mathrm{K}_{2} \mathrm{~F}^{+}$ ions are continuously ejected leaving only $\mathrm{K}_{3} \mathrm{~F}_{2}^{+}$, the strongest $[\mathrm{M}+\mathrm{K}]^{+}$signal is observed. This suggests that $\mathrm{K}_{3} \mathrm{~F}_{2}^{+}$is highly reactive. In Figure $6 c$, ejection of both $\mathrm{K}_{2} \mathrm{~F}^{+}$and $\mathrm{K}_{3} \mathrm{~F}_{2}^{+}$sharply reduces $[\mathrm{M}+\mathrm{K}]^{+}$. The residual $[\mathrm{M}+\mathrm{K}]^{+}$that is observed may come from reaction with low energy $\mathrm{K}^{+}$(see Figure 1) or from even larger adducts. Figure $6 \mathrm{~d}$ provides evidence of the dual effect of the $\mathrm{K}_{2} \mathrm{~F}^{+}$ion; with ejection of both $\mathrm{K}^{+}$and $\mathrm{K}_{3} \mathrm{~F}_{2}^{+}$, abundance $[\mathrm{M}+\mathrm{K}]^{+}$is formed by reaction of $\mathrm{M}$ with $\mathrm{K}_{2} \mathrm{~F}^{+}$but excess $\mathrm{K}_{2} \mathrm{~F}^{+}$remains to suppress FT-ICR detection of $\left[\mathrm{M}+\mathrm{K}^{+}\right.$.

Resonance ejection experiments were also performed on the larger adducts of other potassium salts. In general, with the exception of $\mathrm{K}_{3} \mathrm{~F}_{2}^{+}$, adducts of the form $\mathrm{K}_{3} \mathrm{X}_{2}^{+}$reacted to form $[\mathrm{M}+\mathrm{K}]^{+}$in such low abundance that their contribution at these laser power densities was inconsequential. Thus, in contrast with other particle desorption techniques that may promote formation of larger potassium adducts, only the $\mathrm{K}_{2} \mathrm{X}^{+}$plays a primary role in cation-transfer reactions in the LDI/FT-ICR experiment under our experimental conditions.

Improved LDI/FT-ICR pulse sequence. The double resonance data in Figures 5 and 6 suggest an improved pulse sequence for the LDI/FT-ICR experiment. Clearly, ejection of the uninvolved matrix ions continuously after initiation of the laser pulse is desirable. However, because the presence of $M$ in the cell is transient, there is also no reason that precursor ions such as $\mathrm{K}_{2} \mathrm{X}^{+}$should be retained after the reaction is completed. In the new pulse sequence, $\mathrm{K}^{+}$is ejected during the first $10 \mathrm{~ms}$ after desorption, and $\mathrm{K}_{2} \mathrm{X}^{+}$is then ejected at some time during the second delay before detection when system base pressures are reestablished. Shown in Figure $7 a$ is an LDI/FT-ICR spectra for a mixture of gramicidin-S and $\mathrm{KI}$ acquired with this pulse sequence. In general $[\mathrm{M}+\mathrm{K}]^{+}$signal intensities are a factor of 2 to 5 higher here than when no ejection pulses are used. Shown in Figure $7 \mathrm{~b}$ is the complementary application of this pulse sequence that dramatically illustrates how important the $\mathrm{K}_{2} \mathrm{I}^{+}$is to formation of $[\mathrm{M}+\mathrm{K}]^{+}$. In this case $\mathrm{K}_{2} \mathrm{I}^{+}$ejection during the first $10-\mathrm{ms}$ dclay combined with $\mathrm{K}^{+}$ejection during the second delay serves to eliminate all ion-molecule reaction products from the trapped ion cell.

Comparison to TOF results. It has generally been assumed by both TOF and FT-ICR researchers $[7,8,20]$
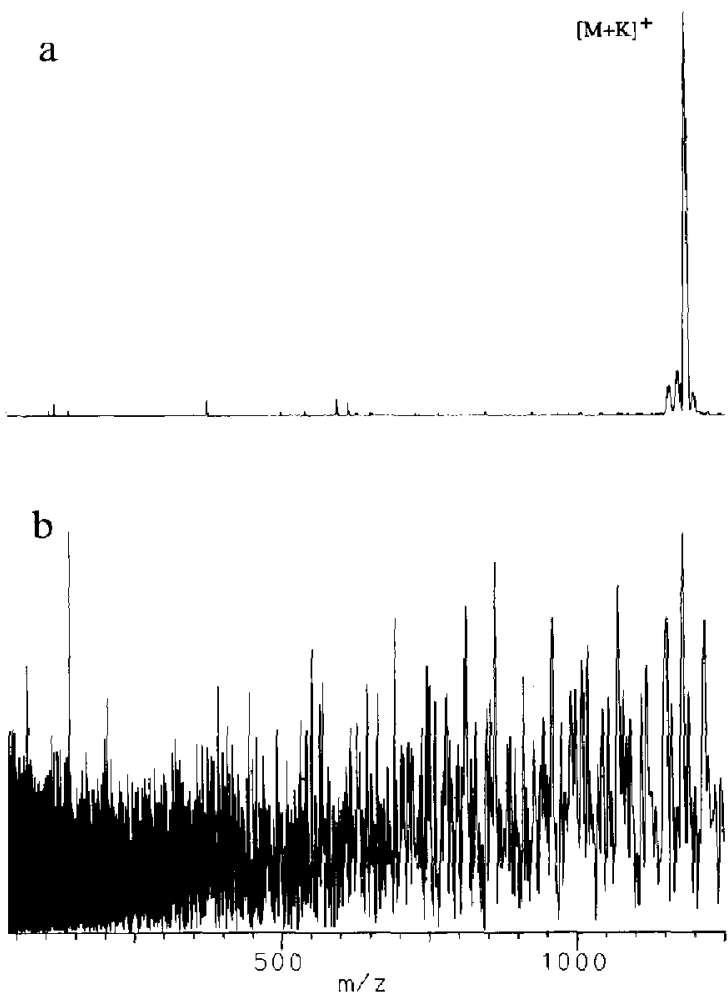

Figure 7. LDI/FT-ICR spectra of gramicidin-S mixed with KI. (a) $\mathrm{K}^{+}$is continuously ejected for $10 \mathrm{~ms}$ after desorption followed by a 150 -ms delay during which $\mathrm{K}_{2} \mathrm{I}^{+}$is ejected prior to delection. (b) The ejection order in a is reversed.

that cation-attachment in the infrared LDI experiment involves the bare cation, $\mathrm{K}^{+}$for example, as the precursor. Although double resonance experiments clearly dismiss this possibility for the LDI/FT-ICR experiment at laser power densities of $10^{8} \mathrm{~W} / \mathrm{cm}^{2}$, these arguments cannot be extended to counter the arguments for $\mathrm{K}^{+}$attachment suggested in the TOF work performed by Kistemaker and Cotter, given differences in mass analyzers. Even the LDI/FT-ICR experiments by Gross might have involved $\mathrm{K}^{+}$attachment because the desorption of low energy $\mathrm{K}^{+}$is greatly favored over adduct formation at $10^{6} \mathrm{~W} / \mathrm{cm}^{2}$.

Finally, some mention should be given to our inability to observe $\mathrm{K}^{+}$reactions to form $[\mathrm{M}+\mathrm{K}]^{+}$by LDI/FT-ICR even though $\mathrm{K}^{+}$is formed at power densities of $3 \times 10^{8} \mathrm{~W} / \mathrm{cm}^{2}$ and detected in high yield at high trap potentials. One explanation might be that $\mathrm{K}^{+}$and DLTDP are not reactive. However, many researchers have demonstrated that $\mathrm{K}^{+}$is highly reactive with certain organic molecules and biomolecules, and specifically, Kistemaker's LDI/TOF crossed beam reactions between $\mathrm{K}^{+}$and desorbed neutrals provide strong evidence that low energy $\mathrm{K}^{+}$does react. We performed a variation on these reactions in FT-ICR; 

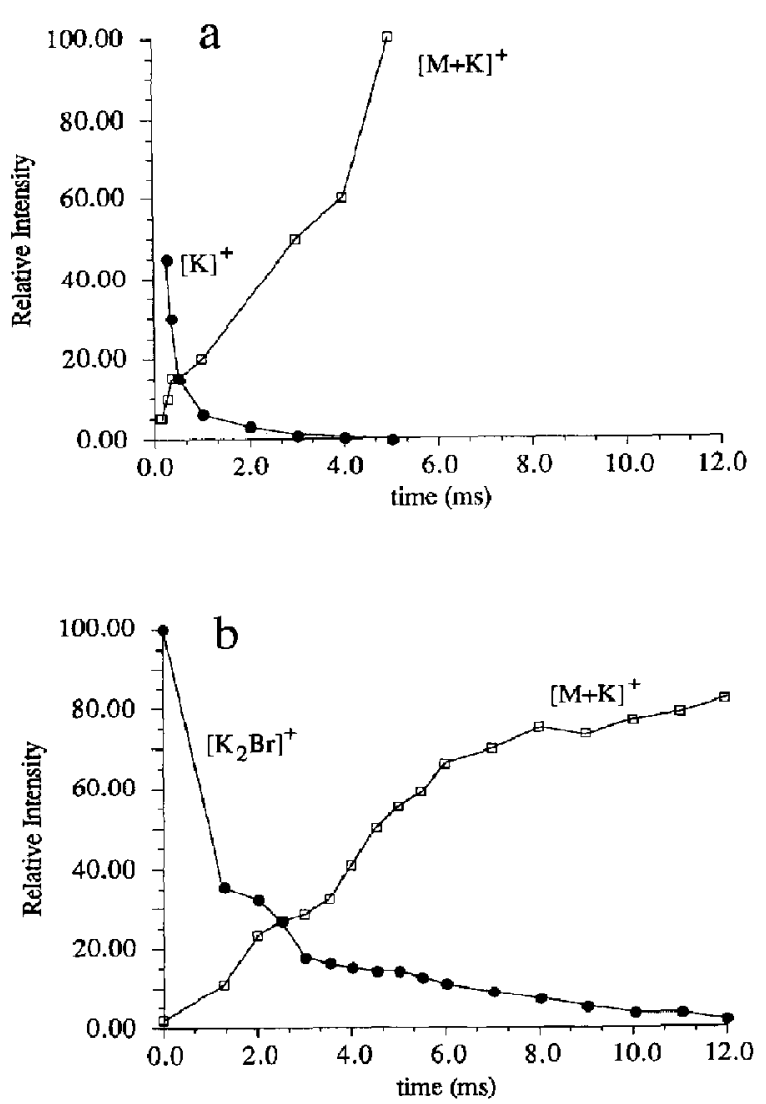

Figure 8. Comparison LDI/FT-ICR profiles for reactions of (a) $\mathrm{K}^{+}$and (b) $\mathrm{K}_{2} \mathrm{Br}^{+}$formed by LDI, trapped in the cell and isolated with ejection sweeps, and allowed to react with DLTDP present at $3 \times 10^{-8}$ torr pressures in a $170^{\circ} \mathrm{C}$ vacuum chamber.

the vacuum chamber was heated to $170^{\circ} \mathrm{C}$ to produce a background pressure of DLTDP of about $3 \times 10^{-8}$ torr. Then following LDI of $\mathrm{KBr}$, either $\mathrm{K}^{+}$or $\mathrm{K}_{2} \mathrm{Br}^{+}$ was selectively trapped and all other ions were removed from the cell with ejection sweeps. During subsequent delays, the $\mathrm{K}^{+}$or $\mathrm{K}_{2} \mathrm{Br}^{+}$was allowed to react with gas-phase DLTDP which, in contrast with the LDI experiment at room temperature, was now continuously present in the gas phase. The reaction profiles presented in Figure 8 indicate that both $\mathrm{K}^{+}$ and $\mathrm{K}_{2} \mathrm{Br}^{+}$react to completion with DLTDP. Many arguments can be made as to why $M$ and high encrgy $\mathrm{K}^{+}$ions products are not detected in the LDI experiment. Two possibilities are an ineffective overlap of gas-phase reactants in the trapped ion cell and an inability to detect $\left[\mathrm{M}+\mathrm{K}^{+}\right.$that might be formed due to incompatible product kinetic energies. However, the behavior of $M$ in the infrared LDI/FT-ICR experiment must be better understood to obtain a complete picture about these ionization and trapping mechanisms.

\section{Acknowledgments}

This work is supported by the Welch Foundation (F-1138), the Arnold and Mabel Beckman Foundation, and the National Science Foundation (CHE9013384) and (CHE9057097).

\section{References}

1. Posthumus, M. A.; Kistemaker, P. G.; Muezelaar, H. L. C. Anal. Chem. 1987, 50, 985-991.

2. Hardin, E. D.; Vestal, M. L. Anal. Chem. 1981, 53, 1492-1497.

3. Cotter, R. J. Anal. Chem. 1984, 56, 485A-504A.

4. Karas, M.; Hillenkamp, F. Anal. Chem. 1988, 60, 2301-2303.

5. Cotter, R. J. Anal. Chem. 1981, 53, 719-720.

6. Balasanmugam, K.; Dang, T. A.; Day, R. J.; Hercules, D. M. Anal. Chem. 1981, 53, 2296-2298.

7. van der Peyl, G. J. Q.; Haverkamp, J.; Kistemaker, P. G. Int. J. Mass Spectrom. Ion Phts, 1982, 42, 125-141.

8. van der Peyl, G. J. Q.; Isa, K.; Haverkamp, J.; Kistemaker, P. G. Org. Mass Spectrom. 1981, 16, 416-420.

9. van Breemen, R. B.; Snow, M.; Cotter, R. J. Int. J. Mass Spectrom. Ion Phys. 1983, 49, 35-50.

10. van der Peyl, G. J. Q.; Van Der Zaude, Kistemaker, P. G. Int. J. Mass Spectrom. Ion Prac. 1984, 62, 51-71.

11. Nuwaysir, L. M.; Wilkins, C. L. In Laser and Spectrometry (Oxford Series on Optical Sciences), Lubman, D. M. Ed.; Oxford University Press: New York, 1989; Chapter 13.

12. McCrery, D. A.; Ledford, E. B. Jr.; Gross, M. L. Anal. Chem. 1982, 54, 1435-1437.

13. Shomo, R. E.; Marshall, A. G.; Weisengerger, C. R. Anal. Chem. 1985, 57, 2740-2744.

14. McCrery, D. A,; Gross, M. L. Anal. Chim, Acta 1985, 128 , 91-108.

15. Wilkins, V. L.; Weil, D. A.; Yang, C. L. C.; Ijames, C. F. Anal. Chem. 1985, 57, 520-524.

16. Sherman, M. G. Jr.; Kingsley, J. R.; Dahlgren, D. A.; Hemmingen, J. C; Mclver, R. T. Jr. Surface Sci. 1985, 148, L25-L32.

17. Coates, M. L.; Wilkins, C. L. Biomed. Env. Mass Spectrom. 1986, 13, 199-204.

18. Bremna, J. T.; Creasy, W. R. Rev. Sui. Instrum. 1988, 59, 873-879.

19. Shomo, R. E. II; Lattimer, R. P.; Marshall, A. G. Int, I. Mass Spectrom. Ion Proc. 1986, 72, 209-217.

20. Chiarelli, M. P.; Gross, M. L. Int. J, Mass Spectrom. Ion Proc. 1987, 78, 37-52.

21. Chiarelli, M. P.; Gross, M. L. J. Phys. Chem. 1989, 93. 3595-3599.

22. Hogan, J. D.; Beu, S. V.; Majidi, V.; Laude, D. A. Jr. Anal. Chem. 1991, 63, 1452-1457.

23. Hogan, J. D.; Laude, D. A. Jr. Anal. Chem., 1991, 63. 2105-2109.

24. Hardin, E. D.; Vestal, M. L. Anal. Chem. 1981, 53, $1492-1497$.

25. Castro, M. E.; Mallis, L. M.; Russell, D. H. I. Am. Chem. Soc, 1985, 107, 5662-5657.

26. Cox, X. B.; Linton, R. W.; Bursey, M. M. Int. I. Mass Spectrom. Ion Proc. 1983, 55, 281-290.

27. Barlak, T. M.; Wyatt, J. R.; Colton, R. J.; DeCorpo, J. J.; Campana, J. F. J. Am. Chem. Soc. 1982, 104, 1212-1215. 
28. Pan, Y.; Cotter, R. J. Proceedings of 39th ASMS Conference on Mass Spectrometry and Allied Topics; Nashville, TN, May 19-24, 1991.

29. Wilk, Z. A.; Viswanadham, S. K.; Sharkey, A. G.; Hercules, D. M. Anal. Chem. 1988, 60, 2338-2346.

30. Asamoto, B.; Young, J. R.; Citerin, R. J. Anal Chem. 1990, 62, 61-70.

31. Beu, S. C.; Laude, D. A. Jr. Int. J. Mass Spectrom. Ion Proc. 1990, 97, 295-310.

32. Lebrillo, C. B.; Amster, T. J.; McIver, R. T. Jr. Int. J. Mass Spectram. Ion Proc. 1984, 87, R7-R13.
33. Kofel, P.; Allemann, M.; Kellerhals, H. P. Int. J. Mass Spectrom. Ion Proc. 1989, 87, 237-247.

34. Kofel, P.; McMahon, J. B. Int. J. Mass Spectrom. Ion Proc. 1990, 98, 1-24.

35. Beu, S. B.; Hendrickson, C.; Vartanian, V.; Laude, D. A. Jr. Int. J. Mass Spectrom. Ion Proc, in press.

36. Demtroder, W.; Jentz, W. Plasma Phys. 1970, 13, 691-703.

37. Vertes, A.; DeWolf, M.; Juhasz; Gijbels, R. Anal. Chem. 1989, 61, 1029-1035.

38. Bolazs, L.; Gijbels, R,; Vertes, A. Anal. Chem. 1991, 63, 314-320. 